\title{
Use of the combined oral contraceptive pill by under 16s
}

\author{
Sam Rowlands, MD MRCGP MFFP, Medical Director; Hassy Devalia, MRPharmS, Operations Director, EPIC, London, UK. \\ Ross Lawrenson, MD MRCGP FAFPHM, Professor of Primary Health Care, Postgraduate Medical School, University of Surrey, \\ Guildford, Surrey, UK.
}

Correspondence: Sam Rowlands, Medical Director, EPIC, Regeneration House, York Way, London, N1 OBB, UK. Tel: 0207713 1118, Fax: 0207713 1119, email: sam.rowlands@epic-uk.org

(Accepted September $5^{\text {th }}, 2000$ )

\begin{abstract}
Summary
The General Practice Research Database was used to examine prescribing of the combined oral contraceptive pill for females aged under 16 in England and Wales in 1997. From these data, calculations were made to estimate prevalence for these countries; family planning clinic return data were combined with the general practice estimates to give an overall figure of 4.2 per 100. This extent of use is low considering the amount of sexual activity now occurring. A weak effect of population density on prescribing was found, with higher rates in the more rural areas.
\end{abstract}

\section{Key words}

contraceptives, oral; family planning: attitudes, knowledge, practice; family practice; physician's practice patterns; prescriptions, drug

\section{Key message points \\ - Prescribing of the combined oral contraceptive pill to girls aged under 16 by general practitioners is low in contrast to the high degree of sexual activity. \\ The prescribing rate is higher in more rural areas.}

\section{Introduction}

There has been a trend of earlier menarche in developed countries during the last century. In the last 40 years the median age of sexual debut has fallen from 21 years to 17 years for women. ${ }^{1}$ Conception rates in the under $16 \mathrm{~s}$ have remained relatively stable (8.9 per 1000 women aged 13-15 years in $1997^{2}$ ), failing to follow marked reductions in all other Western European countries. ${ }^{3}$ Current rates are higher than in any other Western European country and the Health of the Nation target of 4.8 per 1000 was not achieved. The new target is a little less specific: 'to set a firmly established downward trend in the conception rates for under 16 s by 2010 '. 3

Sexual activity was reported by $19 \%$ of British girls in the under 16 age group in 1990/91, ${ }^{1}$ and by $38 \%$ of Scottish girls in this age group in $1998 .{ }^{4}$ Attendance rates at family planning clinics in England by females aged less than 16 rose from 2.1 first contacts per 100 resident population aged $13-15$ in $1989 / 90$, to 7.4 per 100 in 1998/99..$^{5}$ Among 54000 females aged under 16 using family planning clinics in England in 1998/99, 49\% were issued with the condom at their first attendance and $41 \%$ the pill. ${ }^{6} 1996 / 97$ data for England show that $71 \%$ of contraceptive advice given to females aged under 16 is from family planning clinics and $29 \%$ from general practice, ${ }^{3}$ this figure is not totally accurate, however, as some individuals attend both services in the same year. The problem is that teenagers are confused about where they can get contraceptive advice or treatment, whether it is legal for them to do so and how to use it. ${ }^{3}$
The National Survey of Sexual Attitudes and Lifestyles had, and the General Household Survey has, a lower age limit of interviewees of 16 , so these rich sources of data shed no light on contraceptive use in the under 16s. Use of different contraceptive methods by under $16 \mathrm{~s}$ attending general practices is poorly researched. There is very little known about use of the combined oral contraceptive pill by such young women.

The aim of the study was to ascertain the level of combined pill prescribing to women aged under 16 within the context of general practice.

\section{Method}

The General Practice Research Database (GPRD) was used to identify females aged 13-19 years registered at contributing practices in England and Wales during 1997. We have described the GPRD in detail elsewhere. ${ }^{7}$ In summary, the GPRD contains the anonymised records of over eight million patients in the UK and has been validated to contain more than $90 \%$ of all prescriptions issued. ${ }^{8}$

Records of patients with data meeting standards defined by the Medicines Control Agency (GPRD Group) as suitable for research for at least 6 months within the study period, were used. Females aged 16-19 years were included so that comparisons could be made with General Household Survey data. Prescriptions for all currently marketed combined pills and the formulation containing ethinyloestradiol/cyproterone acetate were searched for. Only the first prescription was counted. Annual prevalence rates of pill use were calculated for each age. Contributing practices were categorised by population density in a manner preserving confidentiality of the practices.

\section{Results}

Table 1 shows the prevalence of combined pill prescribing in the GPRD. Of the 24620 young women aged 13-15 years, $1.7 \%$ received prescriptions. Applying similar proportions to the population of England and Wales (930 028 females aged $\left.13-15^{9}\right)$ gives an estimate of 15700 females. The equivalent figure for English $^{6}$ and Welsh (unpublished KT31 returns for Wales) family planning clinics for the 12-month period $1^{\text {st }}$ April 1997 to $31^{\text {st }}$ March 1998 was 23 490. To calculate the estimate of the prevalence of use from both general practice and clinic outlets, it was assumed that women attending GP surgeries and women attending family planning clinics are mutually exclusive. An estimate of the prevalence rate of use from both general practice and clinic outlets is 4.2 per 100 . This compares with an estimate of 30 per 100 for the 16-19 year age group calculated in similar fashion to that for the 13-15 age group.

Combined pill prescribing rates by population density category of contributing practice is shown in Table 2. The most densely populated category was major cities, the intermediate category was suburban areas and the least 
Table 1 Prevalence of combined pill prescribing at GP consultations in GPRD contributing practices in England and Wales: females aged 13-19 in 1997

\begin{tabular}{|c|c|c|c|c|}
\hline $\begin{array}{l}\text { Age } \\
\text { (Years) }\end{array}$ & No. of females receiving pill & No. in age group & Annual prevalence per 100 & $95 \%$ Confidence interval \\
\hline 13 & 13 & 8293 & 0.16 & 0.07 to 0.24 \\
\hline 14 & 85 & 8312 & 1.02 & 0.81 to 1.24 \\
\hline 15 & 318 & 8015 & 4.0 & 3.54 to 4.39 \\
\hline 16 & 915 & 8265 & 11.1 & 10.4 to 11.7 \\
\hline 17 & 1718 & 8720 & 19.7 & 18.9 to 20.5 \\
\hline 18 & 2174 & 8081 & 26.9 & 25.9 to 27.9 \\
\hline 19 & 2183 & 7345 & 29.7 & 28.7 to 30.8 \\
\hline $13-15$ & 416 & 24620 & 1.7 & 1.53 to 1.85 \\
\hline $16-19$ & 6990 & 32411 & 21.6 & 21.1 to 22.0 \\
\hline $13-19$ & 7406 & 57031 & 13.0 & 12.7 to 13.3 \\
\hline
\end{tabular}

densely populated category was rural areas. There was a significant trend $(\mathrm{p}=0.016)$ for the prevalence of females receiving the combined pill and population density; rural areas were observed to have a higher prevalence of females receiving the pill.

\section{Discussion}

Only $4.2 \%$ of $13-15$ year old women received a prescription for the combined pill in 1997, and yet as many as one third of women aged under 16 are sexually active.

The figure of $30 \%$ for the annual prevalence of combined pill use in females aged 16-19 years in England and Wales compares with a point prevalence of $22 \%$ in Great Britain in the 1995 General Household Survey (personal communication, ONS 1999). Published figures are $17 \%$ for 16-17 year olds and 30\% for 18-19 year olds. ${ }^{10}$ One would expect annual prevalence figures to be higher than point prevalence figures; also there will be some inflation of the summated general practice and clinic data due to double counting. Allowing for these two phenomena, the similarity of these two data sources provides some validation for the quality of the electronic data for the under 16 age group.

This estimate of contraceptive uptake is necessarily crude as general practitioner records do not contain information on condom use. The General Household Survey gives us information on the extent of use of the combined pill together with condoms ('Double Dutch') which has now become a fairly common practice, ${ }^{11}$ but only in older teenagers. Also, contraceptive use in teenagers is difficult to measure as it is often very much an on-off phenomenon. Those whose prescriptions were captured in this study would have been unlikely to have continued the pill throughout 1997. Also, the figures from this study will tend to be an underestimate, as some teenagers will be using the formulation for non-contraceptive benefits such as treatment of acne and dysmenorrhoea at least for some of the time. $^{12}$

Reasons for this low use probably include: reluctance to attend a medically orientated service outlet, ${ }^{13}$ risk-taking behaviour, ${ }^{14,15}$ sporadic sexual activity, worries over safety especially after the 1995 pill scare, ${ }^{16}$ and confusion among teenagers as to the law relating to under $16 \mathrm{~s} .{ }^{17}$

The population density effect on prescribing is weak, but may reflect the closer proximity of the general

practitioner's surgery compared to the family planning clinic in more rural areas. Those living in rural areas are presumably more likely to use general practice services because of easier access. However, this lack of clinic facilities in rural areas may lead to poor outcomes; a study in Wessex showed a positive association between distance to the nearest youth-orientated family planning clinic and chance of conceiving plus that conception ending in a maternity rather than a termination. ${ }^{18}$ The teenage conception rate is positively correlated with socioeconomic deprivation ${ }^{18,19}$ deprivation is more common in urban areas.

\section{Conclusion}

The use of the combined pill is low in the under 16s. Low use of effective contraception must partly explain why the UK has the highest teenage birth rate in Western Europe. However, there are many other factors to take into consideration: a lack of 'openness' in discussing sex, ignorance about sex and relationships, poor employment opportunities and poverty. More work is needed on uptake of contraceptive services by young people from different outlets and in areas classified according to a deprivation index.

\section{Acknowledgments}

Tom Gebsattel carried out the computer programming and Peter Thompson the quality assurance. Roger Newson provided the test for trend.

\section{Statements on funding and competing interests}

Funding. None.

Competing interests. None.

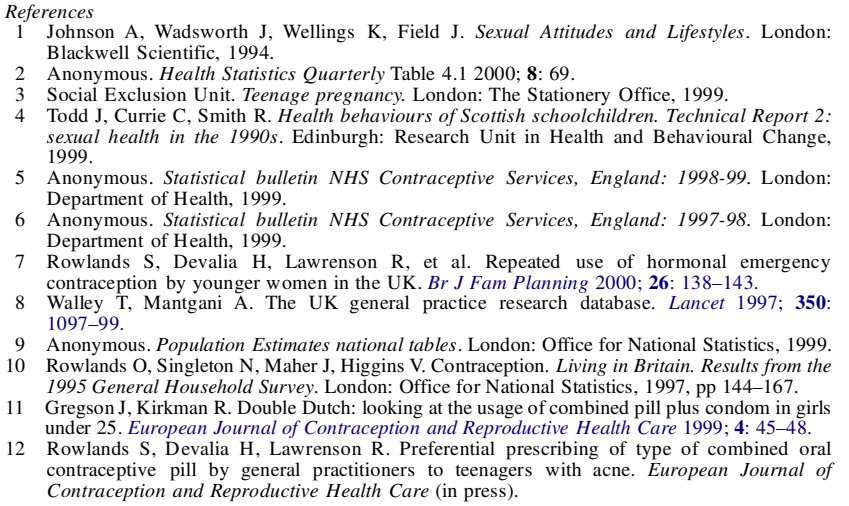

Table 2 Combined pill prescribing rates by population density category of contributing general practice: females aged 13-15

\begin{tabular}{lccc}
\hline $\begin{array}{l}\text { Population density } \\
\left(\text { persons } / \mathrm{km}^{2} \text { ) }\right.\end{array}$ & $\begin{array}{c}\text { No. of females receiving } \\
\text { combined pill }\end{array}$ & Base population & Rate per 100 \\
\hline$<150$ & 55 & 2745 & 2.00 \\
$150-1999.9$ & 283 & 15453 & 1.51 to 2.60 \\
2000 and over & 327 & 21836 & 1.62 to 2.04 \\
\hline
\end{tabular}

Somers' D test for trend $\mathrm{p}=0.016$ 
13 Jacobson LD, Wilkinson C, Pill R. Teenage pregnancy in the United Kingdom in the 1990s: the implications for primary care. Fam Pract 1995; 12: 232-236.

: Routledge, 1993

Burack R. Teenage sexual behaviour: attitudes towards and declared sexual activity. Br J Fam Planning 1999; 24: 145-148.

16 Wellings K, Kane R. Trends in teenage pregnancy in England and Wales: how can we explain them? JRSM 1999; 92: 277-282.
17 Burack R. Young teenagers' attitudes towards general practitioners and their provision of

18 Clements S, Stone N, Diamond I, Ingham R. Modelling the spatial distribution of teenage

Mertion services in London. London: The Health of Londoners Project, 1997. 